\title{
Simultaneous determination of brazilin and protosappanin B in Caesalpinia sappan by ionic-liquid dispersive liquid-phase microextraction method combined with HPLC
}

\author{
Zhaoyang $\mathrm{Xia}^{1 \dagger}$, Dongdong $\mathrm{Li}^{1 \dagger}$, Qing $\mathrm{Li}^{1}$, Yan Zhang ${ }^{3^{*}}$ and Wenyi Kang ${ }^{1,2^{*}}$
}

\begin{abstract}
The conditions of heating, ionic liquid-based ultrasonic-assisted extraction combined with reverse-phase high performance liquid chromatography were optimized to simultaneously isolate and determinate brazilin and protosappanin $\mathrm{B}$ in Caesalpinia sappan. Ionic liquids, including $[\mathrm{BMIM}] \mathrm{Br}$, [BMIM]BF ${ }_{4},[\mathrm{BMIM}] \mathrm{PF}_{6}$ and $\left[\mathrm{HMIM}_{\mathrm{P}} \mathrm{PF}_{6}\right.$, were selected as extraction solvents while methanol, acetone, acetonitrile, ethanol and water were selected as dispersants. The chromatographic column was Purospher star RP-C $C_{18}(250 \mathrm{~mm} \times 4.6 \mathrm{~mm}, 5 \mu \mathrm{m})$, a mixture of methanol and $0.2 \%$ phosphoric acid-water was used as mobile phase at a flow rate $0.65 \mathrm{~mL} / \mathrm{min}$. The result displayed that the extraction yields of brazilin and protosappanin B were highest when the concentration of [BMIM]Br methanol solution as extraction solvent was $0.5 \mathrm{~mol} / \mathrm{L}$ and the solid-liquid ratio was $1: 50(\mathrm{~g} / \mathrm{mL})$. Under the optimal extraction conditions, the contents of brazilin showed a good linearity $(r=1.0000)$ within the range of $1.25-7.50 \mu \mathrm{g}$ with the average recovery of $99.33 \%$, the contents of protosappanin B also showed a good linearity $(r=0.9999)$ within the range of $0.50-3.00 \mu g$ with the average recovery of $98.31 \%$. This experiment, which adopted environmentally friendly reagent as extraction solvent, not only improved the extraction efficiency, but also avoided the environmental pollution caused by organic solvent. Moreover, it was simple and reliable, and can be of important significance in the study of Traditional Chinese Medicine active ingredient extraction methods. The antibacterial activities of the ionic liquids and methanol extracts were determined using the paper disc diffusion method. The ionic liquid extract was found to possess antibacterial activity against Staphylococcus aureus and methicillin-resistant S. aureus (MIC value of $37.5 \mathrm{mg}$ crude drug/mL), $\beta$-Lactamase producing S. aureus (MIC values of $18.8 \mathrm{mg}$ crude drug $/ \mathrm{mL}$ ), but not against E. coli, Extended spectrum $\beta$-Lactamases E. coli and P. aeruginosa. Compared with the ionic liquid extract, the methanol extract was found to have antibacterial activity against S. aureus and methicillin-resistant $S$. aureus (MIC value of $75.0 \mathrm{mg}$ crude drug/mL), $\beta$-Lactamase producing S. aureus (MIC values of $150.0 \mathrm{mg}$ crude drug $/ \mathrm{mL}$ ). However, the same, the methanol extract did not have antibacterial activity against E. coli, Extended spectrum $\beta$-Lactamases E. coli and P. aeruginosa.
\end{abstract}

Keywords: Caesalpinia sappan, Brazilin, Protosappanin B, Ionic liquids, HPLC

\footnotetext{
*Correspondence: snowwinglv@126.com; kangweny@hotmail.com

†Zhaoyang Xia and Dongdong Li contributed equally to this work

${ }^{1}$ Institute of Chinese Materia Medica, Henan University, Kaifeng, Henan 475004, China ${ }^{3}$

Hebei Food Inspection and Research Institute, Shijiazhuang 050091, China

Full list of author information is available at the end of the article
} 


\section{Introduction}

Caesalpinia sappan L. (C. sappan) belonging to family Caesalpiniaceae, an important source for pink and bright reddish-purple colors, has been cultivated in South-East Asia for the production of red dye, which is obtained from its heartwood. The heartwood of this plant has long been used as blood tonic, emmenagogue, and expectorant [1]. Pharmacological researches have shown that C. sappan possesses a wide range of pharmacological activities, including antibacterial $[2,3]$, antioxidant $[4$, $5]$, anti-inflammatory $[6,7]$, anticarcinogenic $[8,9]$ and apoptosis-inducing activities in Hela cells [10].

Brazilin and protosappanin B are two major bioactive homoisoflavones isolated from C. sappan, which are used as the marker components for the quality control of the crude drug in the current version of China Pharmacopoeia [11]. Lee et al. [12] found that brazilin exhibited anti- $\mathrm{T}_{\mathrm{H}} 2$ effects both in vitro and in vivo. Tong et al. [13] found that elimination rates of brazilin and protosappanin $B$ in the streptozotocin-treated rats were slower when compared with those of the normal rats, suggesting that the accumulation of both compounds in diabetic pathologic states and their adverse reactions should be considered. Zeng et al. [14] found that protosappanin B significantly increased cell viability, inhibited cell apoptosis and up-regulated the expression of growth-associated protein 43 . In order to investigate their pharmacological and toxicological properties, we need the methods for rapid, accurate and simultaneous determination of both brazilin and protosappanin B. However, to date, few high-performance liquid chromatography (HPLC) methods for the simultaneous determination of both brazilin and protosappanin $B$ in the crude drug have been reported in the literature [15-17], and also have many shortcomings, for example, low yield, many impurities and poor quality.

Because of their low concentrations, it is very important to improve the limit of detection of these analytes and to achieve good results. To improve the extraction rate, highly toxic solvents are often used. However, the use of toxic solvents can cause pollution to the environment.

In the recent years, more and more researchers have paid increasing attention to a new type of green solventionic liquids. Ionic liquids have many advantages, such as lower melting point, less volatility, higher solubility, chemical stabilization and other characteristics and can be designed to regulate [18]. Ionic liquids have been an alternative to volatile, toxic and hazardous organic solvents in many areas of organic synthesis, electrochemistry, and catalysis [19]. When being used as the extraction solvent in the progress of plant, it can destroy the structure of cellulose, and dissolve cellulose with ionic liquids, ultimately, promoting the dissolution of effective ingredients in the solution [20]. It is not only environmentally friendly, but also can greatly increase the extraction rate of compounds.
In addition to ionic liquids as extractants, the different solvents were also used as disperser solvents to improve the content of brazilin and protosappanin B in C. sappan. Disperser solvents should be able to completely dissolved extraction solvent. The effect of dispersant is to achieve maximum contact area between the extraction solvent and sample. The greater the solubility in water of the dispersant is, the smaller the formation of droplet, and the greater the contact area of the target, and the higher extraction efficiency are.

Recently, ultrasound and temperature [21] have been used to improve the extraction rate. Ultrasound can destroy the cellular structure, leading to the significant increase of mass transfer of analytes into the extractant. Increased extraction temperature is a force driving dispersion of the extraction solvent into an aqueous solution, which can also increase the contact area between the ionic liquids and sample solution and thus, affect the rates of mass transfer of the analytes [22].

According to Ref. [23], this study aimed to evaluate the performance of extraction solvent, disperser solvents, extractant concentration, solid-liquid ratio, ultrasound, temperature and centrifugal rotational speed on the extraction efficiency and to finally find out the optimal extraction conditions, so that the extraction efficiency can be greatly increased.

\section{Materials and methods}

\section{Plant, reagents and solutions}

Heartwood (Caesalpinia sappan)(C. sappan) were collected from Yunnan, China, in July 2012, and identified by a plant scientist, Professor Changqin Li of Henan University. A voucher specimen (No. 20120710) was deposited in the herbarium of Institute of Natural Products, Henan University. The samples were crushed up and dried at room temperature. The air-dried sample was ground into fine powder and passed through a stainless steel sieve. Samples with different sizes were obtained and stored at room temperature in desiccator until use.

1-butyl-3-methylimidazolium hexafluorophosphate ([BMIM] $\mathrm{PF}_{6}$ ), 1-butyl-3- methylimidazolium bromide ([BMIM]Br) and 1-butyl-3-methylimidazolium tetrafluoroborate $\left([\mathrm{BMIM}] \mathrm{BF}_{4}\right)$ were purchased from Merck KGaA (Germany); 1-hexyl-3-methylimidazolium hexafluorophosphate (HMIM] $\mathrm{PF}_{6}$ ) was purchased from Tokyo Chemical industry Co., Ltd.(Tokyo, Japan). Methanol obtained from Avantor Performance Materials, Inc. (Center Valley, PA, USA) was chromatographic grade. Phosphoric acid obtained from Tianjin Fu Chen Chemical Reagent Co., Ltd. (Tianjin, China) was of analytical grade.

Brazilin and protosappanin B as standards were purchased from the Chendu Preferred Biotechnology Co., Ltd. (Chengdu, Sichuan, China).

A mixed stock solution containing brazilin at $0.625 \mathrm{~g} / \mathrm{L}$ and protosappanin B at $0.25 \mathrm{~g} / \mathrm{L}$ was prepared in HPLCgrade methanol. Standard solutions were prepared by 
mixing appropriate amounts of the stock solution with ultra-pure water in $5 \mathrm{~mL}$ volumetric flasks. All the standard solutions were stored at $4{ }^{\circ} \mathrm{C}$.

\section{Apparatus}

The HPLC instrumentation equipped with a vacuum degasser, a quaternary pump (LC-20AD, SHIMADZU), a column oven (CTO-20AC, SHIMADZU), and an autosampler (SIL-20AC, SHIMADZU), was connected to a SPD-20AV UV-Vis detector (SHIMADZU). Chromatographic analysis was performed on a Purospher star RP-C 18 column $(4.6 \mathrm{~mm} \times 250 \mathrm{~mm}, 5 \mu \mathrm{m})$ by using a simultaneous elution and flow-rate programming RP-HPLC method.

\section{Bacterial strains}

Staphylococcus aureus (SA), methcillin-resistant Staphylococcus aureus (MRSA), $\beta$-lactamase-producing Staphylococcus aureus, Escherichia coli (EC), extended spectrum $\beta$-lactamases Escherichia coli $\left(\mathrm{ESBL}_{\mathrm{S}}-\mathrm{EC}\right)$ and Pseudomonas aeruginosa (PA) were used as reference strains, following the guidelines of the Clinical and Laboratory Standards Institute. All the strains were the clinical isolates of bacterial species of interest selected from Huaihe Hospital, Henan University, China, VITEK-AMS identification, the purity greater than $99 \%$.

\section{Chromatographic conditions}

The mobile phase was consisted of methanol- $0.2 \%$ phosphoric acid. The gradient elution steps were set as follows: $0-25 \mathrm{~min}, 30 \%$ methanol, $70 \%$ phosphoric acid at a flow rate of $0.65 \mathrm{~mL} / \mathrm{min}$. The UV detection wavelength was $286 \mathrm{~nm}$. Results were shown in Fig. 1.

\section{The influencing factors of extraction efficiency Selection of type of ionic liquid extraction solvent}

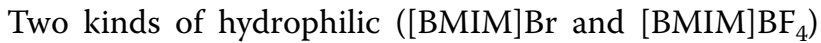
and two kinds of hydrophobic ([BMIM] $\mathrm{PF}_{6}$ and [HMIM] $\mathrm{PF}_{6}$ ) ionic liquids were used as the extraction solvents to research the rapid analysis method for ionic liquid microextraction on C. sappan, to compare the extraction efficiency of the target analytes and to select a suitable type of ionic liquid extraction solvent, respectively.

$100 \mathrm{mg}$ of C. sappan powder (50 mesh) was accurately weighed with five samples, and placed in a centrifuge

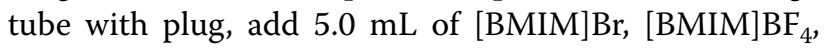
$[\mathrm{BMIM}] \mathrm{PF}_{6}$ and $[\mathrm{HMIM}] \mathrm{PF}_{6}$ methanol solution whose concentrations were both $0.5 \mathrm{~mol} / \mathrm{L}$ precisely, $5.0 \mathrm{~mL}$ of methanol in the control group, ultrasonic processing for $30 \mathrm{~min}$ at $35^{\circ} \mathrm{C}$. The solutions were centrifuged at 5000 $\mathrm{r} / \mathrm{min}$ for $5 \mathrm{~min}$. Solution was filtrated through $0.22 \mu \mathrm{m}$ organic membrane, and the subsequent filtrates were collected. All the samples were automatically injected, and the peak area of each component was recorded.

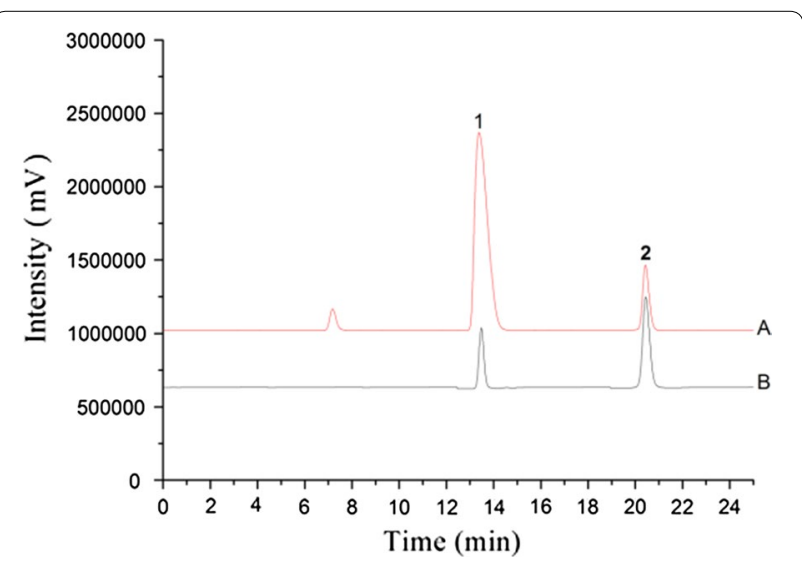

Fig. 1 HPLC chromatograms of reference substance and test solution. A, Test solution of Caesalpinia sappan; B, mixed standard substance; Peak 1, brazilin; Peak 2, protosappanin B

\section{Selection of type of non-ionic liquid disperser solvents}

Five kinds of dispersants (methanol, water, acetone, acetonitrile and ethanol), which could be dissolved [BMIM] Br, were investigated on the extraction efficiency of brazilin and protosappanin B in C. sappan. These dispersants were used as dispersant. The final concentration of the extract was made at $0.5 \mathrm{~mol} / \mathrm{L}$ and the extraction rates of the target analytes were compared, respectively.

$100 \mathrm{mg}$ of C. sappan powder (50 mesh) was accurately weighed with five samples, and $5.0 \mathrm{~mL}$ of methanol, water, acetone, acetonitrile and ethanol were added precisely with ultrasonic processing for $30 \mathrm{~min}$ at $35^{\circ} \mathrm{C}$, and then centrifuged for $5 \mathrm{~min}$ at $5000 \mathrm{r} / \mathrm{min}$ for $5 \mathrm{~min}$.

\section{Selection of extract concentration}

The influences of [BMIM] $\mathrm{Br}$ methanol at concentrations of $0.1,0.2,0.3,0.4,0.5,0.6,0.7,0.8$ and $0.9 \mathrm{~mol} / \mathrm{L}$ on the extraction rate were investigated, respectively. $100 \mathrm{mg}$ of C. sappan powder (50 mesh sieve) was accurately weighed for nine samples, $5.0 \mathrm{~mL}$ of [BMIM] Br methanol solution was added, precisely, and with ultrasonic processing for $30 \mathrm{~min}$ at $35{ }^{\circ} \mathrm{C}$, and then centrifuged for $5 \mathrm{~min}$ at $5000 \mathrm{r} / \mathrm{min}$ for $5 \mathrm{~min}$.

\section{Selection of mesh}

Mesh of crushed herbs have some influences on the extraction rate, the smaller the powder is, the higher the extraction rate is. However, powder is easy to gather into ball when it is very small. Thus, the extraction rate would be affected by the powder size.

The effects of 10, 24, 40, 50, 70 and 90 mesh sieve powders the extraction efficiency of target analytes were assayed. $100 \mathrm{mg}$ of C. sappan powder was accurately 
weighed for nine samples, $5.0 \mathrm{~mL}$ of [BMIM] $\mathrm{Br}$ methanol solution was adjusted to the concentration of $0.5 \mathrm{~mol} / \mathrm{L}$ precisely with ultrasonic processing $30 \mathrm{~min}$ at of $35{ }^{\circ} \mathrm{C}$, and centrifuged at $5000 \mathrm{r} / \mathrm{min}$ for $5 \mathrm{~min}$.

\section{Selection of solid-liquid ratio}

The solid-liquid ratios at 1:20, 1:30, 1:50, 1:75, 1:100 and $1: 125(\mathrm{~g} / \mathrm{mL})$ were selected to investigate their effects on extract fluence of brazilin and protosappanin B in C. sappan. The C. sappan powder (70 mesh sieve) was accurately weighed for six different samples, $5.0 \mathrm{~mL}$ of [BMIM] Br methanol solution at concentration of $0.5 \mathrm{~mol} / \mathrm{L}$ was added precisely with ultrasonic processing $30 \mathrm{~min}$ at $35^{\circ} \mathrm{C}$, and then centrifuged at $5000 \mathrm{r} / \mathrm{min}$ for $5 \mathrm{~min}$.

\section{Selection of ultrasonic time}

Generally, the longer the ultrasonic time is, the higher extraction efficiency is. However, a long ultrasonic time can destroy the structure of the target compound. In this experiment, ultrasonic times for 10, 20, 30, 40, 50 and 60 min were examined for their effects on the extract efficiency of brazilin and protosappanin B in C. sappan.

$100 \mathrm{mg}$ of C. sappan powder (70 mesh sieve) in six samples were adjusted to the concentration at $0.5 \mathrm{~mol} / \mathrm{L}$ with [BMIM] Br methanol solution precisely, and solidliquid ratio was formulated into 1:50 sample and treated with ultrasonic extraction times for 10, 20, 30, 40, 50 and $60 \mathrm{~min}$ at 35 , and centrifuged at $5000 \mathrm{r} / \mathrm{min}$ for $5 \mathrm{~min}$.

\section{Selection of ultrasonic temperature}

Because of the boiling point of ionic-liquid at $75{ }^{\circ} \mathrm{C}$, the highest temperature of ultrasonic temperature and heating temperature were below the boiling point. Concentration of C. sappan powder (70 mesh sieve) in [BMIM] $\mathrm{Br}$ methanol solution was $0.5 \mathrm{~mol} / \mathrm{L}$ for five samples with ultrasonic extraction $50 \mathrm{~min}$ at $30,40,50,60$, and $70{ }^{\circ} \mathrm{C}$, respectively, The solutions were centrifuged at $5000 \mathrm{r} /$ $\min$ for $5 \mathrm{~min}$.

\section{Selection of heating time}

Six samples of C. sappan powder (70 mesh sieve) in [BMIM] Br methanol solution at the concentration of $0.5 \mathrm{~mol} / \mathrm{L}$ were heated for $10,20,30,40,50$ and $60 \mathrm{~min}$ at $50{ }^{\circ} \mathrm{C}$, and the solutions were centrifuged for $5 \mathrm{~min}$ at $5000 \mathrm{r} / \mathrm{min}$ for $5 \mathrm{~min}$.

\section{Selection of heating temperature}

Five samples of $C$. sappan powder (70 mesh sieve) in [BMIM] Br methanol solution at the concentration of $0.5 \mathrm{~mol} / \mathrm{L}$ were heated for $50 \mathrm{~min}$ at $30,40,50,60$, and $70{ }^{\circ} \mathrm{C}$ for $50 \mathrm{~min}$ The solutions were then centrifuged for $5 \mathrm{~min}$ at $5000 \mathrm{r} / \mathrm{min}$ for $5 \mathrm{~min}$.

\section{Selection of extraction method}

Through the above tests, the optimum conditions for ultrasonic extraction were determined as follows: disperser solvent, the [BMIM]Br methanol solution; the concentration of $C$. sappan powder (70 mesh sieve), $0.5 \mathrm{~mol} / \mathrm{L}$; solid-liquid ratio, $1: 50$ sample; ultrasonic extraction time, $50 \mathrm{~min}$ at $50{ }^{\circ} \mathrm{C}$, and centrifuge for $5 \mathrm{~min}$ at $5000 \mathrm{r} / \mathrm{min}$. The optimum method for heat extraction as follows: the concentration of [BMIM] Br methanol solution, both $0.5 \mathrm{~mol} / \mathrm{L}$ which was added precisely to $C$. sappan powder (70 mesh sieve); a solid-liquid ratio, 1:50 sample; extraction time, $50 \mathrm{~min}$; extraction temperature; $60{ }^{\circ} \mathrm{C}$, and centrifuge for $5 \mathrm{~min}$ at $5000 \mathrm{r} / \mathrm{min}$. The optimum method for reflux extraction as follows: [BMIM] $\mathrm{Br}$ methanol solution at concentration of $0.5 \mathrm{~mol} / \mathrm{L}$ was added precisely to $C$. sappan powder (70 mesh sieve), a solid-liquid ratio, 1:50 sample with reflux; extraction time, $50 \mathrm{~min}$; and centrifuged at $5000 \mathrm{r} / \mathrm{min}$ for $5 \mathrm{~min}$.

\section{Selection of centrifugal rotational speed}

In this experiment, centrifugal rotational speeds at 3000 , $4000,5000,6000,7000$ and $8000 \mathrm{r} / \mathrm{min}$ were investigated to examine the influences of the centrifugal rotational speed on the experimental results.

The [BMIM] Br methanol solution at concentration of $0.5 \mathrm{~mol} / \mathrm{L}$, was precisely added to C. sappan powder (70 mesh sieve) in a solid-liquid ratio of 1:50. The sample was extracted with ultrasonic extraction for $50 \mathrm{~min}$ at $50{ }^{\circ} \mathrm{C}$, and centrifuged for at different rotational speeds for $5 \mathrm{~min}$.

\section{Antibacterial activities of different extracts Preparation of the tested substance solutions}

According to the optimal extraction conditions, C. sappan powder was extracted and collected for the subsequent filtrate, the filtrate decompression was enriched in vacuo, and diluted with [BMIM] $\mathrm{Br}$ methanol solution whose concentration was $0.5 \mathrm{~mol} / \mathrm{L}$ to $0.2 \mathrm{~mol} / \mathrm{L}$. Methanol extract was the same as the above.

\section{Paper disc diffusion method}

The initial concentration of the tested substance solutions was $300 \mathrm{mg}$ crude $\mathrm{drug} / \mathrm{mL}$. Sterile paper discs were loaded with $8 \mu \mathrm{L}$ of solution and dried in a sterile room. At the same time, sterile paper discs were loaded with $8 \mu \mathrm{L}$ of brazilin solution or protosappanin B solution, whose concentrations were both $10 \mathrm{mg} / \mathrm{mL}$. Streptomycin was used as positive control and paper discs treated with methanol or [BMIM]Br methanol solution were used as the negative control. The paper disc diffusion method was used to determine antibacterial activity based on the method described by Ali et al. [24] The plates were then incubated at $37{ }^{\circ} \mathrm{C}$ for $18 \mathrm{~h}$ in a 
water-jacket thermostatic incubator. Inhibition zone diameters (IZ) of the disc were measured and recorded at the end of the incubation time [25].

\section{Determination of minimum inhibitory concentration (MIC)}

The tested samples were dissolved in [BMIM]Br methanol solution and in methanol for brazilin, protosappanin B and streptomycin. Twofold serial dilutions of each compound were prepared [26]. According to the operation described above, the plates were then incubated at $37^{\circ} \mathrm{C}$ for $18 \mathrm{~h}$ in the incubator. The MIC was defined as the lowest concentration of tested substance solutions, brazilin, protosappanin B and streptomycin at which no visible growth was observed. All the operations were performed under sterile conditions [27].

\section{Results and discussion}

\section{Linear relationship study}

According to the chromatographic condition and the sample processing method, a series of the mixed stock solutions with the injection volumes of 2, 4, 6, 8, 10 and $12 \mu \mathrm{L}$ were analyzed by HPLC. The injection quality was taken as abscissa $(\mathrm{X}, \mu \mathrm{g})$, peak area value was taken as ordinate $(\mathrm{Y})$, to linear fit. Brazilin regression equation is $\mathrm{Y}=1653011.383 \mathrm{X}+75841, r=1.0000$, and the linear range is $1.25-7.50 \mu \mathrm{g}$. Protosappanin $\mathrm{B}$ regression equation is $\mathrm{Y}=1186313.371 \mathrm{X}+15359, r=1.0000$, the linear range is $0.5-3.0 \mu \mathrm{g}$.

\section{The influencing factors of extraction efficiency Selection of type of ionic liquid extraction solvent}

The comparison in extraction efficiency between ionic liquid and methanol was shown in Fig. 2. When [BMIM] $\mathrm{Br}$ methanol solution was used as extraction solvent, extraction rates of brazilin and protosappanin B were significantly higher than that of methanol, which were
1.52 and $0.85 \%$, respectively. While the extraction rates of the other three kinds of ionic liquids were lower than that of methanol. The extraction rate of the [HMIM] $\mathrm{PF}_{6}$ was the lowest one, which were 0.80 and $0.43 \%$, respectively. The cation of [BMIM] Br, [BMIM] $\mathrm{BF}_{4}$ and [BMIM] $\mathrm{PF}_{6}$ was 1-butyl-3-methylimidazolium, the solubility of ionic liquid depended on its anion. The solubility of ionic liquids directly affected the extraction rate of the target compound. At the same time, the damages of ionic liquids with different $\mathrm{pH}$ values to medicinal cells were also different, which immediately affected the dissolution rate of target analyte [28]. From the extraction rates of target compounds which were affected by [BMIM] $\mathrm{PF}_{6}$ and $[\mathrm{HMIM}] \mathrm{PF}_{6}$, with the extension of alkyl chain, the enrichment factor of the target compounds was decreased, which indicated that different alkyl chains had an influence on the density of ionic liquids, and water solubility etc. [29]. Therefore, in the following experiments, [BMIM] Br was chosen as the extraction solvent.

\section{Selection of type of non-ionic liquid disperser solvent}

Different dispersants on dispersion ability of [BMIM] Br are different, which have an influence on the extraction rates of target compounds. As it can be seen in Fig. 3, disperser solvent is required to be able to completely dissolve the extraction solvent and easy to dissolve the sample. At the same time, the chromatographic conditions and the determination of analytes need to be well [30]. Methanol, water, acetone, ethanol and acetonitrile were used as the disperser solvents to determine the effect of disperser solvents on extraction efficiencies of two compounds.

Extraction rate was the highest one when methanol was used as the disperser solvent, followed by water. When acetone was applied as the disperser solvent, the extraction rate decreased, as compared with the methanol and

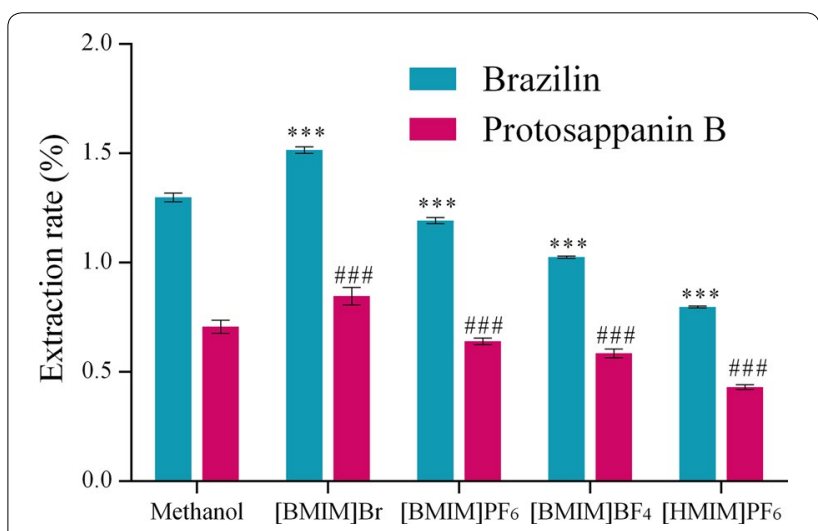

Fig. 2 Influences of ionic liquids on the extraction rate of the compound. Note: compared with methanol ${ }^{* * *} P \leq 0.001$ or $\left.{ }^{\# \#} P \leq 0.001\right)$

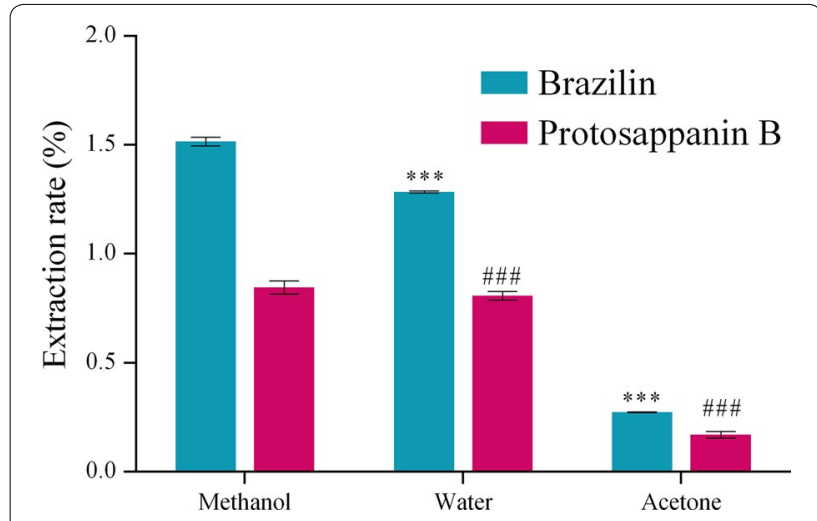

Fig. 3 Influence of dispersants on the extraction rate of the compound. Note: compared with methanol ( ${ }^{* * P} P \leq 0.001$ or $^{\# \# \# P} \leq 0.001$ ) 
a great height miscellaneous peak was appeared in about $5 \mathrm{~min}$. When ethanol and acetonitrile were applied as the disperser solvent, a pair of shoulder peaks appeared in brazilin and protosappanin B corresponding time.

\section{Selection of extractant concentration}

In Fig. 4, with the increase of concentration of [BMIM] $\mathrm{Br}$ methanol solution, the extraction rates of two compounds were correspondingly increased. When the concentration reached $0.5 \mathrm{~mol} / \mathrm{L}$, extraction rate was the maximum, which were 1.52 and $0.85 \%$, respectively. After this, the extraction rate was reduced the increasing concentration. In view of this, the $0.5 \mathrm{~mol} / \mathrm{L}$ of [BMIM] $\mathrm{Br}$ methanol solution was finally chosen as the extractant in the experiment. Because the extractant viscosity was increased with the increase in extractant concentration, the extraction efficiency was affected, thus, the extraction rate turned to a downward trend after reaching the optimum concentration.

\section{Selection of mesh}

The effect of changes in mesh on extraction rate was shown in Fig. 5. With the increase of mesh sieve, the extraction rates of two kinds of compounds were correspondingly increased. The extraction rates of two compounds reached the maximum at 70-mesh. But when the mesh was too small, sample particle started to gather into cluster in ionic liquids, the target compound could not be extracted, the extraction efficiency was affected. Thus, their extraction rates were both increased firstly and then decreases finally.

\section{Selection of solid-liquid ratio}

The influence of solid-liquid ratios on the extraction rate was shown in Fig. 6 . When the quality of medicinal powder was the same, the extraction rate of two kinds of

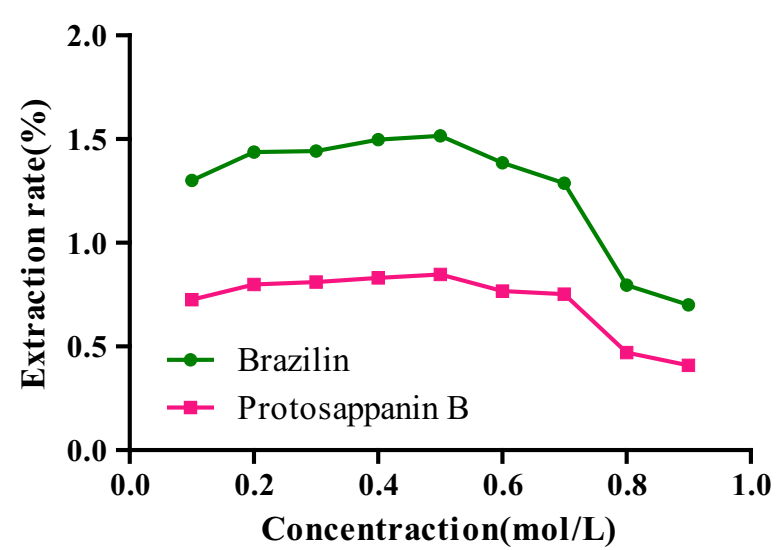

Fig. 4 Influence of extractant concentrations on the extraction rate of the compounds

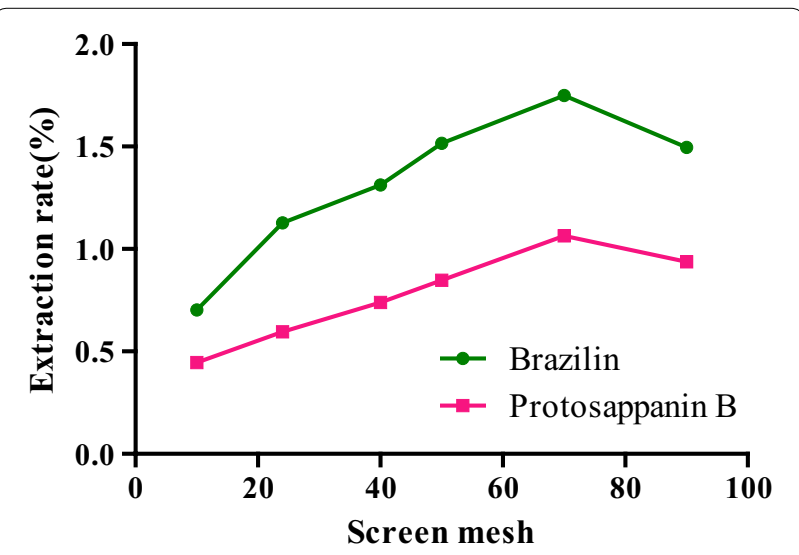

Fig. 5 Influence of meshes on the extraction rate of the compounds

compounds corresponding increased with the increase of the volume of extractant. The extraction rates of brazilin and protosappanin $B$ reached the maximum at the solid-liquid ratio of 1:50. When the solid-liquid ratio continued to increase, the curve tended to a balance. Within certain range of solid-liquid ratio, the dissolution rates of two compounds were increased with the increase in solid-liquid ratio raised. When the ratio continued to increase, the target compound in the medicinal materials were almost extracted completely by ionic liquid, both solubility and dissolution rate reached the maximum.

\section{Selection of ultrasonic time}

The effect of ultrasonic times on the extraction rate was shown in Fig. 7. Along with the extension of time, extraction rates of brazilin and protosappanin $B$ were increased. The extraction rates of brazilin and protosappanin $\mathrm{B}$ reached the maximum after $50 \mathrm{~min}$. When the ultrasonic time continued to increase, the target compound in the

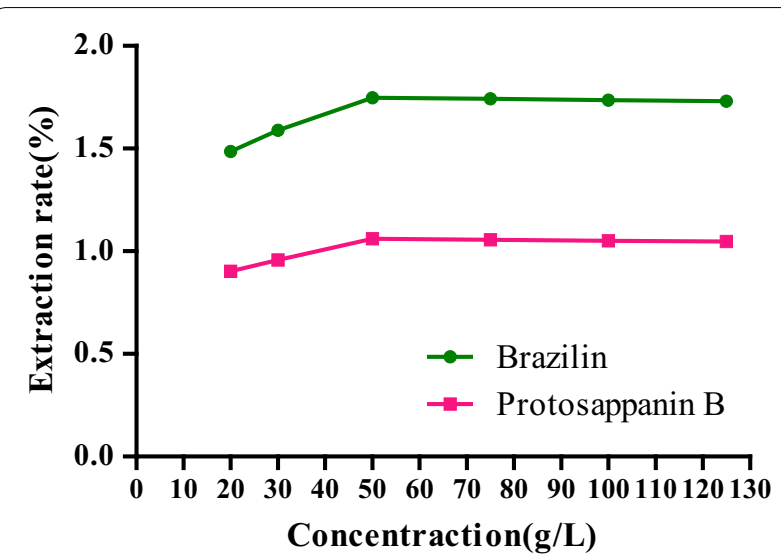

Fig. 6 Influence of solid-liquid ratios on the extraction rate of the compounds 
sample was destroyed, causing the extraction rate turned to a downward trend, but the peak area of impurity was increased. In view of this, the ultrasonic time of $50 \mathrm{~min}$ was the optimal time in the experiment.

\section{Selection of ultrasonic temperature}

The effect of ultrasonic temperatures on the extraction rate was shown in Fig. 8. Along with increasing of ultrasonic temperature, the extraction rates of two compounds were increased. The extraction rate of brazilin reached the maximum at $50{ }^{\circ} \mathrm{C}$ while that of protosappanin $\mathrm{B}$ reached the maximum at $60^{\circ} \mathrm{C}$, but was increased only slightly as compared with that at $50{ }^{\circ} \mathrm{C}$. When the ultrasonic temperature continued to increase, effective components in the sample were destroyed, resulting in downward trend of the extraction rates of brazilin and protosappanin $\mathrm{B}$. The extraction rate of brazilin was dropped sharply at $60{ }^{\circ} \mathrm{C}$ as compared with that at $50{ }^{\circ} \mathrm{C}$, thus, the ultrasonic temperature of $50{ }^{\circ} \mathrm{C}$ was determined as the optimum temperature.

\section{Selection of heating time}

The effect of heating times on the extraction rate was shown in Fig. 9. With the extension of time, extraction rates of the two compounds were increased slowly, extraction rates of brazilin and protosappanin $B$ reached the maximum at $50 \mathrm{~min}$. When the heating time continued to increase, the target compound in the sample was destroyed, resulting in the downward trend of the extraction rates of brazilin and protosappanin $B$. Thus, the heating time of $50 \mathrm{~min}$ determined as the optimal time.

\section{Selection of heating temperature}

The effect of heating temperatures on the extraction rate was shown in Fig. 10. The extraction rates of the two

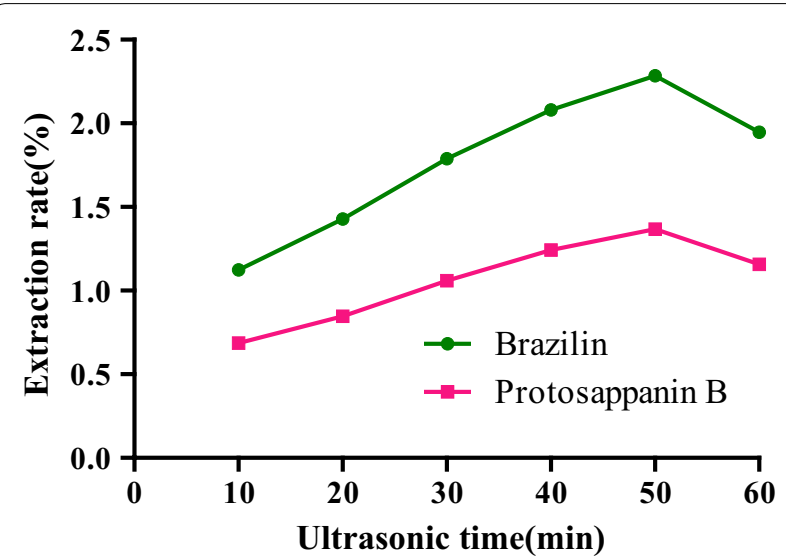

Fig. 7 Influence of ultrasonic times on the extraction rate of the compounds

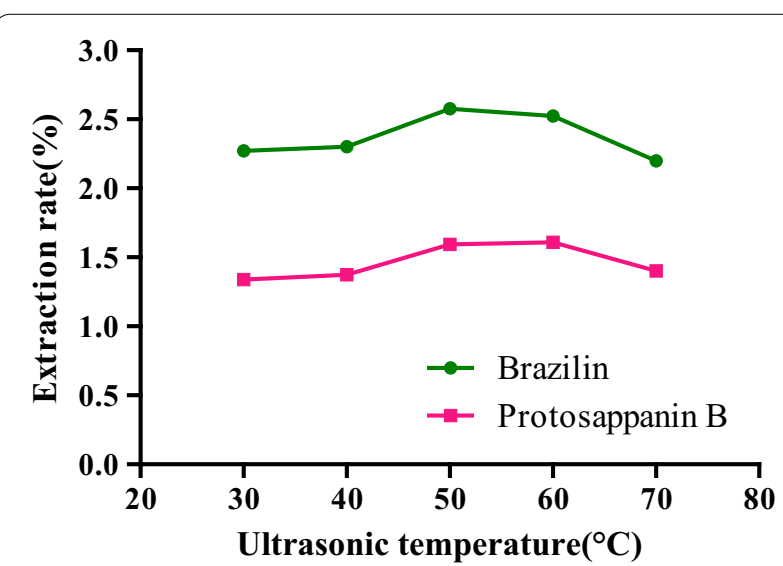

Fig. 8 Influence of ultrasonic temperatures on the extraction rate of the compounds

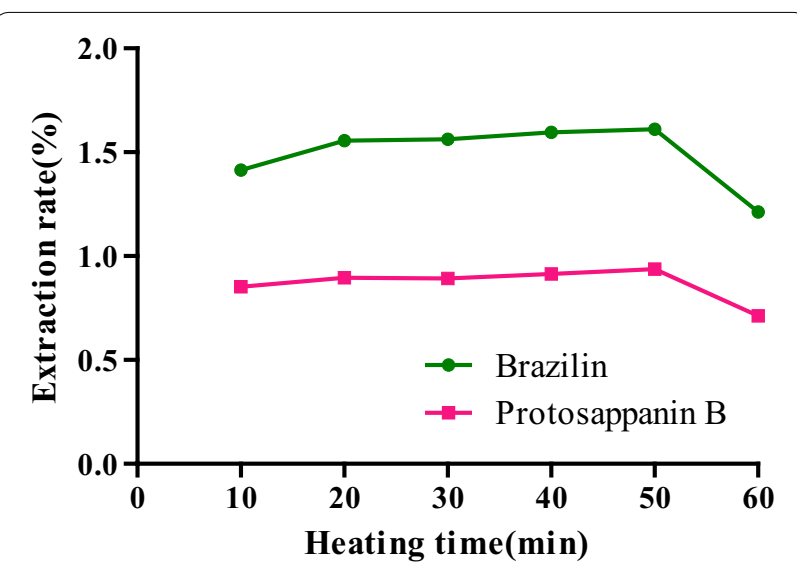

Fig. 9 Influence of heating times on the extraction rate of the compounds

compounds were increased rapidly with increasing the heating temperature. The extraction rate of brazilin and protosappanin $\mathrm{B}$ reached the maximum at $60{ }^{\circ} \mathrm{C}$. When the heating temperature continued to increase, effective components in the sample were destroyed, resulting in the downward trend of the extraction rates. Thus, the heating temperature of $60{ }^{\circ} \mathrm{C}$ was determined as the optimum temperature.

\section{Selection of extraction method}

In Fig. 11, the extraction rates of brazilin and protosappanin B were 1.99 and $1.22 \%$ with the optimum heating extraction method, respectively. The extraction rates were 2.58 and $1.59 \%$ with the optimal ultrasonic extraction method, respectively. The extraction rates were 2.60 and $1.61 \%$ with the heating reflux extraction methods under the condition of the same amount of time, respectively. When the heating reflux extraction was adopted to 


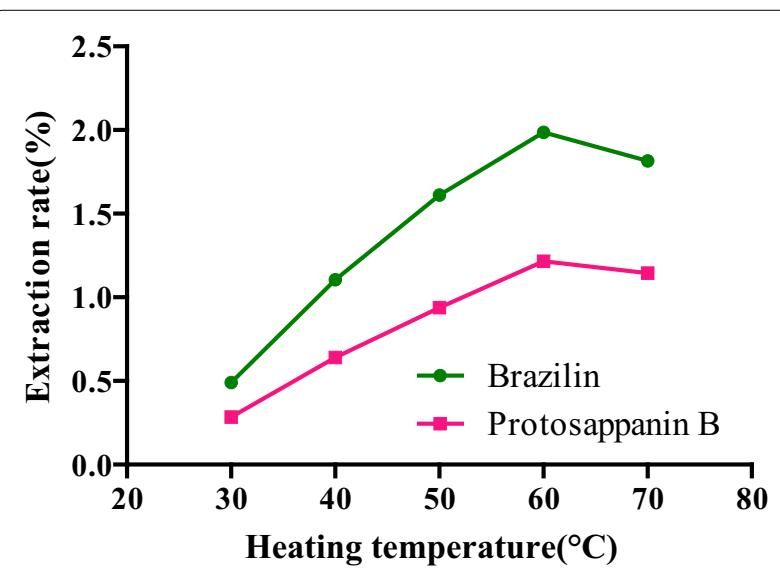

Fig. 10 Influence of heating temperatures on the extraction rate of the compounds

extract the active ingredient, the extraction rates of the two compounds were both higher than that of ultrasonic extraction. However, the heating reflux extraction operation had some defects of assembly. So, the ultrasonic extraction was adopted finally.

\section{Selection of centrifugal rotational speed}

The effect of the centrifugal rotational speeds on the extraction rate was shown in Fig. 12. With the increase of centrifugal rotational speed, the extraction rates of two compounds were raised. The extraction rates of brazilin and protosappanin $B$ reached the maximum, which were 2.61 and $1.58 \%$ at $6000 \mathrm{r} \mathrm{min}^{-1}$, respectively. When the influence of the centrifugal rotational speed on the extraction rate was investigated, results showed that the minimal extraction rates were 2.41 and $1.53 \%$ at the speed of $3000 \mathrm{r} \mathrm{min}{ }^{-1}$, respectively, as compared with the maximum, which were reduced by only 0.2 and $0.05 \%$. In the

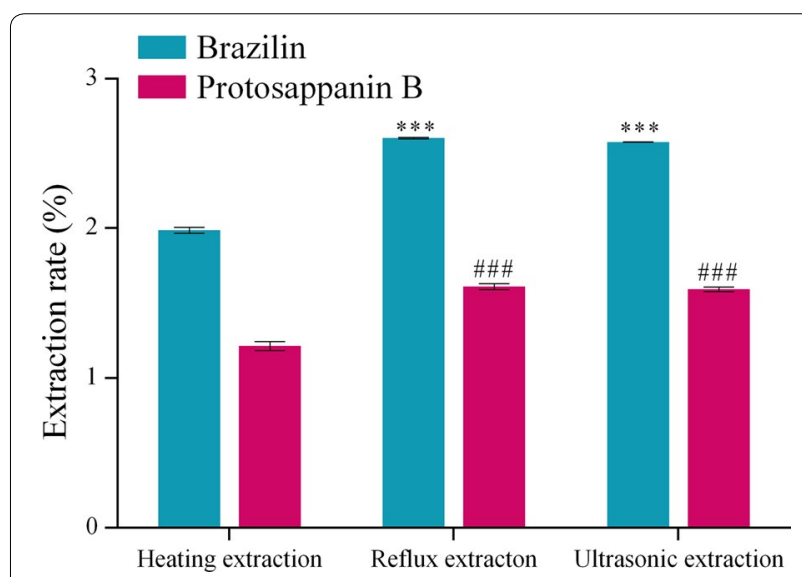

Fig. 11 Influence of extraction methods on the extraction rate of the compound. Note: compared with heating extraction ${ }^{* * *} P \leq 0.001$ or $\left.{ }^{\# \#} P \leq 0.001\right)$

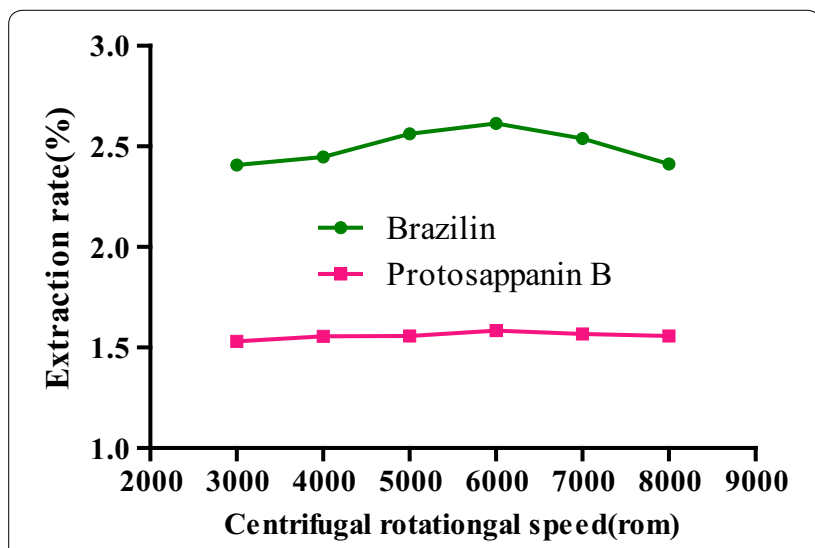

Fig. 12 Influence of centrifugal rotational speeds on the extraction rate of the compounds

experiment, centrifugal rotational speeds at $6000 \mathrm{r} \mathrm{min}^{-1}$ was chosen as the optimal centrifugal rotational speed finally.

\section{Evaluation of method performance Precision experiments}

The mixed reference substance solution with the injection volume of $10 \mu \mathrm{L}$ was determined by HPLC, respectively, according to the chromatographic conditions. The relative standard deviations (RSD) were calculated to be 0.29 and $0.30 \%$, respectively.

\section{Stability experiments}

The test sample solution with the injection volume of $10 \mu \mathrm{L}$ was determined at $0,3,6,9,12$ and $24 \mathrm{~h}$ by HPLC, respectively, according to the chromatographic conditions. RSDs were calculated to be 0.94 and $1.79 \%$, respectively.

\section{Repeatability experiments}

Six samples were selected on the same time, and $10 \mu \mathrm{L}$ of these solutions was injected into chromatographic instrument for analysis. The RSDs were calculated to be 1.33 and $1.26 \%$, respectively.

\section{Recovery rate experiments}

Six samples of C. sappan powder $(60.00 \mathrm{mg})$ were divided into two parallel copies and three levels. The standard substances of brazilin and protosappanin B were added whose qualities were 80, 100 and $120 \%$ test sample. Each test solutions with the injection volume of $10 \mu \mathrm{L}$ was determined by HPLC. The recovery rate, the average recovery rate and the RSD were calculated. The average recovery rate of brazilin was $99.33 \%$, the RSD was $1.34 \%$; the average recovery rate of protosappanin B was $98.31 \%$, and the RSD was $1.80 \%$. 


\section{Determined quality of sample}

The optimum extraction conditions could be obtained by the test of the influencing factors on extraction efficiency, the peak areas of brazilin and protosappanin B in the methanol extract and the optimum extraction conditions of ionic liquid extract were determined, respectively. The quantities of brazilin and protosappanin B were calculated by the regression equation, the percentages of the corresponding materials in crude drug were finally concluded. In Table 1, the percentages of brazilin and protosappanin $\mathrm{B}$ in the ionic liquid extract were higher than those in the methanol extract.

\section{Antibacterial activities of different extracts}

The inhibition zone In Table 2, ionic liquid extract had a strong antibacterial activity against SA, MRSA and $\beta$-Lactamase producing $S$. aureus. The inhibition zone diameter against MRSA was the largest one, which was $19 \mathrm{~mm}$. Methanol extract also had antibacterial activities against SA, MRSA and $\beta$-Lactamase producing S. aureus. The inhibition zone diameter against MRSA was the largest one, which was $11 \mathrm{~mm}$. The inhibition zone diameter of brazilin against $\beta$-Lactamase producing $S$. aureus was the largest one, which was $18 \mathrm{~mm}$. However, protosappanin B did not have antibacterial activity. Streptomycin

Table 1 Percentage of composition of brazilin and protosappanin B in Caesalpinia sappan $(n=3)$

\begin{tabular}{lllll}
\hline \multicolumn{2}{l}{ Methanol extractant } & & \multicolumn{2}{l}{$\begin{array}{l}\text { [BMIM]Br methanol solution } \\
\text { extractant }\end{array}$} \\
\cline { 1 - 2 } \cline { 1 - 1 } $\begin{array}{l}\text { Percentage } \\
\text { of brazilin (\%) }\end{array}$ & $\begin{array}{l}\text { Percentage } \\
\text { of protosappa- } \\
\text { nin B (\%) }\end{array}$ & $\begin{array}{l}\text { Percentage } \\
\text { of brazilin (\%) }\end{array}$ & $\begin{array}{l}\text { Percentage } \\
\text { of protosap- } \\
\text { panin B (\%) }\end{array}$ \\
\hline 1.30 & 0.71 & 2.61 & 1.59 \\
\hline
\end{tabular}

against gram-negative bacteria was valid, but the sample solution and standard solution against gram-negative bacteria were invalid.

The MIC In Table 3, ionic liquid extract had lower MIC values against $\beta$-Lactamase producing S. aureus, in which MIC value were only $18.8 \mathrm{mg}$ crude drug/ mL. Compared with methanol extract, antimicrobial activities of ionic liquid extract against SA, MRSA and $\beta$-Lactamase producing $S$. aureus were stronger than those of methanol extract. But the MIC values of ionic liquid extract against SA, MRSA and $\beta$-Lactamase producing $S$. aureus were higher than those of brazilin and streptomycin.

\section{Conclusions}

The main objectives of this study were to compare thirteen kinds of extraction methods for developing a simple and efficient method for simultaneous determination of brazilin and protosappanin $B$ with HPLC. The results showed that this was the optimal test methods, which was successfully applied to analyze the target analytes. The average recovery rates of brazilin and protosappanin B were 99.33 and $98.31 \%$, respectively. Simultaneous use of ultrasound-assisted, temperature-controlled and ionic-liquid dispersive liquid-phase microextraction reduced the danger of organic solvent. This method is not only environmentally friendly, but also greatly increases the extraction rate of compounds.

\section{Abbreviations \\ HPLC: high performance liquid chromatography; [BMIM]PF : 1-butyl-3-meth- ylimidazolium hexafluorophosphate; [BMIM]Br: 1-butyl-3- methylimidazolium bromide; [BMIM]BF 4 : 1-butyl-3-methylimidazolium tetrafluoroborate; [HMIM] $\mathrm{PF}_{6}$ : 1-hexyl-3-methylimidazolium hexafluorophosphate.}

Table 2 The inhibition zone of extract and standard solutions against SA, MRSA, $\beta$-Lactamase producing S.aureus, EC, ESBLs-EC and PA

\begin{tabular}{|c|c|c|c|c|c|c|c|}
\hline \multirow[t]{3}{*}{ Sample } & \multicolumn{7}{|l|}{ Inhibition zone (mm) } \\
\hline & \multirow[t]{2}{*}{ Concentration } & \multicolumn{6}{|c|}{ Bacteria } \\
\hline & & SA & MRSA & $\beta$-Lactamase producing S. aureus & $\mathrm{EC}$ & ESBLs-EC & PA \\
\hline Ionic liquid extract & 2.4 mg crude drug/disc & 15 & 19 & 14 & - & - & - \\
\hline Methanol extract & & 10 & 11 & 8 & - & - & - \\
\hline Brazilin & $80 \mu \mathrm{g} / \mathrm{disc}$ & 12 & 12 & 18 & - & - & - \\
\hline Protosappanin B & & - & - & - & - & - & - \\
\hline Streptomycin & $16 \mu \mathrm{g} / \mathrm{disc}$ & 18 & 9 & 19 & 19 & 8 & 19 \\
\hline Ionic liquid & - & - & - & - & - & - & - \\
\hline Methanol & & - & - & - & - & - & - \\
\hline
\end{tabular}

Paper diameter is $6 \mathrm{~mm}$; -: no activity; streptomycin: positive control; methanol and ionic liquid: negative control 
Table 3 The MIC of extract and standard solutions against SA, MRSA and $\beta$-Lactamase producing S. aureus

\begin{tabular}{lllrr}
\hline MIC & Concentration & \multicolumn{2}{l}{ Bacteria } & \\
\cline { 3 - 5 } & & SA & MRSA & B-Lactamase producing S. aureus \\
\hline lonic liquid extract & $\mathrm{mg}$ crude drug $/ \mathrm{mL}$ & 37.5 & 37.5 & 18.8 \\
Methanol extract & $\mathrm{mg} / \mathrm{mL}$ & 75.0 & 75.0 & 150.0 \\
Brazilin & & 2.5 & 2.5 & 2.5 \\
Streptomycin & 0.06 & 0.5 & 0.03 \\
\hline
\end{tabular}

\section{Authors' contributions}

WYK and YZ conceived the research idea. ZYX, DDL and QL conducted the experiments, collected the plant specimens, analyzed and interpreted the data as well as prepared the first draft. WYK and YZ critically read and revised the paper. All the authors read and approved the final manuscript.

\section{Author details}

1 Institute of Chinese Materia Medica, Henan University, Kaifeng, Henan 475004, China. ${ }^{2}$ Kaifeng Key Laboratory of Functional Components in Health Food, Kaifeng, Henan 475004, China. ${ }^{3}$ Hebei Food Inspection and Research Institute, Shijiazhuang 050091, China.

\section{Competing interests}

The authors declare that they have no competing interests.

\section{Funding}

This work was supported by Henan Province University Science and Technology Innovation Team (16IRTSTHN019), Natural Science Foundaion of Henan Province (162300410038), Science and Technology Innovation Team of Kaifeng City (2016-124), Kaifeng City Science and Technology Innovation Talent (1509010), Key Project in Science and Technology Agency of Kaifeng (1603111).

\section{Publisher's Note}

Springer Nature remains neutral with regard to jurisdictional claims in published maps and institutional affiliations.

Received: 23 January 2017 Accepted: 23 October 2017

Published online: 13 November 2017

\section{References}

1. Zhao HX, Bai H, Wang WS, Li W, Koike K (2008) A new homoisoflavan from Caesalpinia sappan. J Nat Med 62:325-327

2. Batubara I, Mitsunaga T, Ohashi H (2010) Brazilin from Caesalpinia sappan wood as an antiacne agent. J Wood Sci. 56:77-81

3. Xu HX, Lee SF (2004) The antibacterial principle of Caesalpina sappan. Phytother Res 18:647-651

4. Tuekaew J, Siriwatanametanon N, Wongkrajang Y, Temsiririrkkul R, Jantan I (2014) Evaluation of the antioxidant activities of Ya-hom Intajak, a Thai herbal formulation, and its component plants. Trop J Pharm Res 13:1477-1485

5. Lee MJ, Lee HS, Kim H, Yi HS, Park SD, Moon HI, Park WH (2010) Antioxidant properties of benzylchroman derivatives from Caesalpinia sappan $\mathrm{L}$. against oxidative stress evaluated in vitro. J Enzyme Inhibition Med Chem 25:608-614

6. Jung EG, Han Kl, Kwon HJ, Patnaik BB, Kim WJ, Hur GM et al (2015) Anti-inflammatory activity of sappanchalcone isolated from Caesalpinia sappan L. in a collagen-induced arthritis mouse model. Arch Pharm Res 38:973-983

7. Wu SQ, Otero M, Unger FM, Goldring MB, Phrutivorapongkul A, Chiari C et al (2011) Anti-inflammatory activity of an ethanolic Caesalpinia sappan extract in human chondrocytes and macrophages. J Ethnopharmacol 138:364-372
8. Zhang H, Piao JH, Ren LS, Tang Y, Tian F (2002) A study on aqueous extract of lignum sappan inducing HL-60 cell apoptosis. Chin Remedies Clin 2:16-17

9. Tian T, Zhang PT, Yu MW, Liu YH (2010) Effects of lignum sappan on growth and metastases of lewis lung carcinoma at different phases in C57BL/6 mice. Chin J Intergrated Tradit West Med 30:733-737

10. Hung TM, Dang NH, Nguyen TD (2014) Methanol extract from Vietnamese Caesalpinia sappan induces apoptosis in HeLa cells. Biol Res 47:20-24

11. Editorial Committee of Chinese Pharmacopoeia (2010) Chinese pharmacopoeia. China Medical Science and Technology Press, Beijing

12. Lee CC, Wang CN, Kang JJ, Liao JW, Chiang BL, Chen HC et al (2012) Antiallergic asthma properties of Brazilin through inhibition of $\mathrm{T}_{\mathrm{H}} 2$ responses in T cells and in a murine model of asthma. J Agric Food Chem 60:9405-9414

13. Tong XZ, Zhu H, Shi Y, Xu HT, Wang B, Zhao JH (2013) An LC/MS/MS method for simultaneous quantitation of two homoisoflavones: protosappanin B and brazilin with hypoglycemic activity in rat plasma and its application to a comparative pharmacokinetic study in normal and streptozotocin-treated rats. J Ethnopharmacol 148:682-690

14. Zeng KW, Liao LX, Zhao MB, Song FJ, Yu Q (2015) Jiang Y, at el. Protosappanin B protects $P C 12$ cells against oxygen-glucose deprivation-induced neuronal death by maintaining mitochondrial homeostasis via induction of ubiquitin-dependent p53 protein degradation. Eur J Pharmacol 751:13-23

15. Chen YP, Bi D, Tu PF (2010) Quality standard of sappan lignum. Chin J Chin Mater Med 35:2068-2071

16. Chen XM, Hu YG, Li MP, Feng YL, Zhang SW (2012) Determination of brazilin and protosappanin B in sappan lignum by high performance liquid chromatography. Chin J Anal Lab 4:98-101

17. Jia YY, Li Y, Song Y, Zhao JY, Dou F, Sun Y et al (2014) A simple high-performance liquid chromatographic method for the determination of brazilin and its application to a pharmacokinetic study in rats. J Ethnopharmacol 151:108-113

18. Sun ZM, Liu BY, Zhao DS (2008) Synthesis of fine chemicals in ionic liquids. Fine Chem 25:212-216

19. Rajesh GK, Sarah NW, Kenneth KL (2011) Highly efficient synthesis of amides via Ritter chemistry with ionic liquids. Tetrahedron Lett $52: 867-871$

20. Liu W, Guo XC, Li DD, Yang HS, Chen YY, Wei JF et al (2015) Determination of oleanic acid and paeoniflorin in Paeonia lactiflora by ultrasoundassisted ionic liquid-reversed phase liquid chromatography. Chin J Chin Mater Med 40:24-30

21. Berton P, Martinis EM, Martinez LD, Wuilloud RG (2012) Selective determination of inorganic cobalt in nutritional supplements by ultrasoundassisted temperature-controlled ionic liquid dispersive liquid phase microextraction and electrothermal atomic absorption spectrometry. Anal Chim Acta 713:56-62

22. Maryam R, Sudabeh HE, Behruz B, Hanieh G (2014) Ultrasound-assisted temperature-controlled ionic-liquid dispersive liquid-phase microextraction method for simultaneous determination of anethole, estragole, and para-anisaldehyde in different plant extracts and human urine: a comparative study. Anal Bioanal Chem 406:4501-4512

23. Wei JF, Cao PR, Wang JM, Kang WY (2016) Analysis of tilianin and acacetin in Agastache rugosa by high-performance liquid chromatography with ionic liquids-ultrasound based extraction. Chem Cent J 10:76-85 
24. Ali NA, Julich WD, Kusnick C, Lindequist U (2001) Screening of Yemeni medicinal plants for antibacterial and cytotoxic activities. J Ethnopharmacol 74:173-179

25. Liu G, Ma YM, Zhang HC (2013) Isolation, identification and antimicrobial activities of endophytic fungi from Cephalotaxus fortunei. Chin Pharm J 48:165-170

26. Yagi S, Chrétien F, Duval RE et al (2012) Antibacterial activity, cytotoxicity and chemical constituents of Hydnora johannis, roots. S Afr J Bot 78:228-234

27. Li CQ, Zhao L, Kang WY (2011) Antimicrobial activity of Salvia miltiorrhiza and different processed products. Chin Tradit Pat Med 33:1948-1951
28. Zhang YF, Li CJ, Bao FS, Zhang YA (2005) Classification, synthesis and application of ionic liquids. Chin J Chem Edu 2:7-12

29. Liu X, Fu R, Li M, Guo LP, Yang L (2013) lonic liquid-based dispersive liquid-liquid microextraction coupled with capillary electrophoresis to determine drugs of abuse in urine. Chin J Anal Chem 12:1919-1922

30. Liu JY, Zuo LH, Jia XX, Guo XJ (2012) Determination of P-coumaric acid in rat plasma by dispersive liquid-liquid microextraction-HPLC. J Shenyang Pharm Univ 7:529-534

\section{Submit your manuscript to a SpringerOpen ${ }^{\circ}$ journal and benefit from:}

- Convenient online submission

- Rigorous peer review

- Open access: articles freely available online

- High visibility within the field

- Retaining the copyright to your article

Submit your next manuscript at springeropen.com 